\title{
Meniscectomia Parcial como Modelo Experimental de Osteoartrite em Coelhos e Efeito Protetor do Difosfato de Cloroquina
}

\section{Partial Meniscectomy as an Experimental Model of Osteoarthritis in Rabbits and Protector Effect of Chloroquine Diphosphate}

\author{
Ana Paula P. Velosa ${ }^{(1)}$, Adriana M. de Oliveira ${ }^{(2)}$, Solange Carrasco $^{(3)}$, Vera Luíza Capelozzi ${ }^{(4)}$, \\ Walcy Rosolia Teodoro $^{(1)}$, Natalino H. Yoshinari ${ }^{(5)}$
}

\section{RESUMO}

Objetivo: Estabelecer as alterações morfológicas e o remodelamento do tecido cartilaginoso na progressão da osteoartrite $(\mathrm{OA})$ experimental para estudar o efeito do difosfato de cloroquina na cartilagem osteoartrítica. Métodos: A osteoartrite experimental foi induzida em coelhos por meio de meniscectomia parcial. Para analisar a evolução da doença experimental foram estudados três grupos de dez animais, sacrificados a 3, 14 e 22 semanas de indução da doença. Para avaliar o efeito do difosfato de cloroquina um grupo de animais $(n=6)$ foi tratado preventivamente com $3 \mathrm{mg} / \mathrm{kg}$ ao dia, iniciados um mês antes da indução da osteoartrite, e mantidos até o sacrifício (22 semanas). Realizou-se análise histológica das articulações (H\&E, tricrômico de Masson) e imunofluorescência para colágeno dos tipos I, II e XI. A intensidade da agressão articular foi quantificada pelo escore de Mankin. Resultados: $\mathrm{O}$ modelo experimental reproduziu todas as alterações morfológicas observadas na osteoartrite humana. Animais que receberam difosfato de cloroquina não desenvolveram lesões histológicas observadas na OA. Neste grupo houve significante preservação da estrutura da cartilagem articular $(\mathrm{p}<0,0001)$, conservação da celularidade $(\mathrm{p}<0,0001)$, proteoglicanas, demonstrados pela coloração de azul de anilina $(\mathrm{p}<0,005)$ e integridade da linha de crescimento $(\mathrm{p}<0,001)$, além da inibição da formação de osteófitos, do bloqueio da neoformação óssea e do não-aparecimento de colágeno tipo I (tecido osteocartilaginoso). Conclusão: $\mathrm{O}$ modelo experimental de meniscectomia parcial reproduz de forma gradativa as alterações morfológicas encontradas na osteoartrite, e estudos preliminares com o difosfato de cloroquina sugerem tratar-se de medicamento barato e com grande potencial de emprego como droga condroprotetora.

Palavras-chave: osteoartrite experimental, cartilagem articular, difosfato de cloroquina, condroprotetor, remodelamento.

\begin{abstract}
Objective: The aim of this study was to develop an experimental model of osteoarthritis $(O A)$ that could reproduce morphologic alterations viewed in this disease and to study the effect of chloroquine diphosphate on cartilage remodeling. Methods: osteoarthritis was induced in rabbits by performing partial meniscectomy. To establish the experimental disease evolution, three groups of ten animals were sacrificed at 3, 14, 22 weeks after disease induction. To evaluate the effect of chloroquine diphosfate in $O A$ progression, a group of six animals was treated preventively with $3 \mathrm{mg} / \mathrm{kg} /$ day, started one month prior to osteoarthritis induction and kept until the day of sacrifice (22 weeks). Histopathological (Masson trychrome, H\&E), biochemical and immunofluorescence analyses to types $I, I I$ and XI collagens were made in all animals. Mankin's score was employed to quantify the severity of articular damage. Results: The experimental model reproduced all of the alterations observed in osteoarthritis. Animals treated with chloroquine diphosfate did not develop morphological changes found in $O A$. There was significant preservation of articular cartilage tissue $(p<0,0001)$, maintenance of cellular morphology $(p<0,0001)$, proteoglicans, as demonstrated by aniline blue coloration $(p<0,005)$ and tidemark protection $(p<0,001)$, besides inhibition of osteophytes formation and absence of type I collagen expression. Conclusion: The experimental model of partial meniscectomy reproduces gradually, all the cartilage morphologic changes found in human osteoarthritis. Preliminary study done with choroquine diphosfate indicates that it is a cheap and effective drug to act as condroprotective agent in $O A$.
\end{abstract}

Keywords: experimental osteoarthritis, articular cartilage, chloroquine diphosfate, condroprotector, remodeling.

Recebido em 05/04/07. Aprovado, após revisão, em 29/09/07. Declaramos a inexistência de conflitos de interesse.

Laboratório de Investigação Médica, disciplina de Reumatologia, Departamento de Clínica Médica e Departamento de Patologia da Faculdade de Medicina da Universidade de São Paulo, SP, Brasil.

1. Doutora em Ciências pela Faculdade de Medicina da Universidade de São Paulo (FMUSP).

2. Bióloga estagiária da Fundação do Desenvolvimento Administrativo (Fundap)

3. Bióloga da FMUSP.

4. Professora-associada do Departamento de Patologia da FMUSP.

5. Professor-associado da disciplina de Reumatologia da FMUSP.

Endereço para correspondência: Natalino Hajime Yoshinari, Faculdade de Medicina da Universidade de São Paulo, Av. Dr. Arnaldo, 455, $3^{\circ}$ andar, CEP 01246-009,

São Paulo, SP, e-mail: matrix@lim17.fm.usp.br. 


\section{INTRODUÇÃO}

A cartilagem articular, que recobre o osso subcondral das articulações diartrodiais, é freqüentemente acometida na osteoartrite $(\mathrm{OA})$. Esse tecido, extremamente diferenciado, é avascular, formado por pequena porcentagem de células, os condrócitos, e vasta matriz extracelular constituída principalmente por água e macromoléculas, como proteoglicanas e colágenos.

A matriz fibrilar da cartilagem é composta primariamente de colágeno tipo II, principal molécula do arcabouço fibrilar, representando cerca de $80 \%$ a $85 \%$ do conteúdo total de colágeno do tecido cartilaginoso ${ }^{(1-3)}$. Além deste, são encontrados colágenos adicionais, como os tipos VI, IX, X, XI e XII, considerados constituintes menores ${ }^{(4)}$. Os tipos IX e XI, embora representem de $5 \%$ a $10 \%$ do total de colágeno da cartilagem, são extremamente importantes, uma vez que o colágeno tipo XI, localizado no interior das fibrilas, regula o diâmetro da fibrila heterotípica, e o tipo IX é importante para manter a integridade da matriz cartilaginosa, pois faz ligações cruzadas com o colágeno tipo II, na superfície dessa fibrila, além de interagir com outras moléculas da matriz ${ }^{(1,3,5-11)}$.

Em processos artrósicos, ocorrem um intenso remodelamento da matriz extracelular, como tentativa de reparação tecidual, incluindo a síntese de colágeno tipo II nas fases iniciais da doença, e reexpressão do procolágeno tipo IIA, forma normalmente expressa em células condroprogenitoras ${ }^{(12-14)}$. Foram descritos aumento de colágeno tipo VI em cartilagem artrósica humana e em modelo de meniscectomia parcial em coelhos, nas regiões pericondrocitárias, e expressão do gene para colágeno tipo $\mathrm{X}$, nas áreas de nova formação de osso $^{(15-17)}$. A expressão de colágenos I e III, normalmente não presentes no tecido cartilaginoso, principalmente em fibrilações e osteófitos, reflete uma reparação tecidual inadequada, com a formação de fibrocartilagem ${ }^{(12,13,18,19)}$. Durante a evolução da OA, a degradação dos componentes matriciais, principalmente os colágenos II, IX e XI e proteoglicanos, supera a tentativa de regeneração tecidual, culminando na falência cartilaginosa e no remodelamento do osso subcondral.

$\mathrm{O}$ tratamento da $\mathrm{OA}$ visa não apenas ao controle sintomático da dor, mas à prevenção da evolução da doença por intermédio da utilização de fármacos de ação lenta, potencialmente modificadores da evolução clínica. Dentre os fármacos de ação lenta, destacam-se os antimaláricos, como o difosfato de cloroquina, droga que já vem sendo utilizada em alguns serviços de reumatologia no País, no tratamento de pacientes com OA, com resultados extremamente promissores.

Em virtude da escassez de trabalhos científicos relativos à terapêutica e ao modo de ação do difosfato de cloroquina na $\mathrm{OA}$ e das dificuldades de realizarem-se estudos em cartilagem osteoartrítica humana, desenvolvemos um modelo experimental de OA em coelhos, por meio de meniscectomia parcial do joelho, com base no modelo inicialmente desenvolvido por Moskowitz et al. ${ }^{(20)}$, porém modificado de modo a promover alterações morfológicas progressivas e mais lentas, à semelhança daquelas encontradas em humanos.

O objetivo deste trabalho foi estudar as alterações morfológicas e o remodelamento do tecido cartilaginoso observados na OA experimental induzida pela meniscectomia parcial de joelho em coelhos e analisar o efeito terapêutico do difosfato de cloroquina na prevenção da OA experimental.

\section{MATERIAL E MÉTODOS}

\section{MODELO EXPERIMENTAL DE OSTEOARTRITE}

\section{ANIMAIS}

Foram utilizados coelhos machos, da linhagem Nova Zelândia, com peso médio de 2.500 gramas. Para estudar a evolução das alterações patológicas na doença experimental, os coelhos foram divididos em quatro grupos com dez animais cada, sendo um grupo controle não-operado e três grupos experimentais que foram sacrificados com 3, 14 e 22 semanas de OA induzida. Na época dos sacrifícios, os animais utilizados como controle apresentavam a mesma faixa etária e o mesmo peso dos animais submetidos à OA experimental.

\section{MENISCECTOMIA PARCIAL}

Para a indução experimental de OA, empregamos a metodologia proposta por Moskowitz et al. ${ }^{(20)} \mathrm{com}$ modificações. Os animais foram anestesiados, via intramuscular, com xilazina ( $5 \mathrm{mg} / \mathrm{kg}$ ) e ketamina $(50 \mathrm{mg} / \mathrm{kg})$, e a microcirurgia foi realizada sob condições estéreis. Por meio de uma incisão parapatelar lateral, no joelho direito, foi removido um quarto anterior do menisco lateral, sem cortar ou lesar os ligamentos. Após o procedimento cirúrgico, os animais foram soltos nas gaiolas, sem imobilização da região operada.

Após o período de 3, 14 e 22 semanas, os animais de cada grupo foram sedados com solução aquosa a $2 \%$ de 
cloridrato de 2-(2,6-xilidino) 5,6-dihidro-4H 1,3-tiazina l M (Rompum ${ }^{\circledR}$, Bayer do Brasil S.A.) e, após 5 minutos, anestesiados com cloridrato de cetamina (Ketalar, ParkDavis) $1 \mathrm{M}$, sendo em seguida sacrificados por injeção letal de cloridrato de cetamina.

\section{AVALIAÇÃo DAS ALTERAÇÕES MACROSCÓPICAS}

Imediatamente após o sacrifício dos coelhos, os joelhos direito e esquerdo foram expostos e examinados quanto à presença de osteófitos e de lesões na superfície da cartilagem articular. Em relação à ocorrência de lesões, a cartilagem articular foi classificada em: normal quando a superfície da cartilagem se encontrasse com aspecto regular; fibrilada se houvesse irregularidades na superfície da cartilagem articular, e fibrilada com exposição do osso quando as lesões se aprofundavam até a região óssea.

\section{EXAME ANATOMOPATOLÓGICO}

Os fragmentos de cartilagem, previamente fixados em formol a 10\%, foram desidratados por concentrações crescentes de álcool etílico (75\% a 100\%) e xilol, incluídos em parafina e seccionados em cortes de $5 \mu \mathrm{m}$, como procedimentos histológicos de rotina. As preparações foram coradas pela hematoxilina-eosina e pelo tricrômico de Masson e examinadas por microscopia ótica. Para a caracterização histopatológica da OA, uma série de quatro secções histológicas de cada animal, representativas de regiões diferentes da cartilagem do côndilo e do platô, foi analisada, de acordo com a existência das seguintes alterações: modificação no padrão de coloração pelo tricrômico de Masson na matriz extracelular; presença de fibrilações, contorno ondulado e/ou descontínuo da superfície cartilaginosa; existência de áreas com agrupamentos celulares (clusters), e/ou de regiões despovoadas de condrócitos visualizadas pela coloração H\&E.

\section{PROTOCOLO TERAPÊUTICO PARA ESTUdO \\ DO DIFOSFATO DE CLOROQUINA}

Foram utilizados coelhos da linhagem Nova Zelândia, machos $(\mathrm{n}=15)$ com peso médio de 2.500 gramas, divididos em três grupos:

A- grupo controle, não operado $(\mathrm{n}=3)$;

B- grupo operado, sem tratamento $(\mathrm{n}=6)$;

C- grupo operado e tratado $(n=6)$.

O grupo de animais tratados recebeu $3 \mathrm{mg} / \mathrm{kg} /$ dia de difosfato de cloroquina via oral, adicionado em bebedouros logo pela manhã. Essa dose foi estabelecida de acordo com a dose do fármaco utilizado para tratamento em humanos, adaptada ao peso do animal. O tratamento foi iniciado um mês antes da meniscectomia e mantido por 22 semanas. Após esse período, os animais de cada grupo foram sedados de acordo com os procedimentos de rotina e sacrificados. Posteriormente, as articulações dos joelhos direito e esquerdo foram coletadas e fixadas em formol a $10 \%$ para análise anatomopatológica e imunofluorescência.

\section{AVAliaçÃo histológica}

As articulações dos joelhos dos animais fixadas em formol $10 \%$ foram descalcificadas com ácido nítrico $7 \%$ por cerca de uma semana e submetidas a procedimentos histológicos de rotina. Cortes longitudinais das articulações de aproximadamente $5 \mu \mathrm{m}$ foram corados pela hematoxilinaeosina e pelo tricrômico de Masson e examinados por microscópio óptico.

Para a avaliação histológica dos cortes de articulações dos coelhos meniscectomizados sem ou com tratamento com difosfato de cloroquina, foi utilizado o escore de Mankin com modificações ${ }^{(21)}$. As lâminas foram avaliadas por dois observadores independentes que quantificaram a gravidade das lesões em relação à estrutura da cartilagem, à celularidade, à degeneração matricial pela coloração com azul de anilina e à integridade da linha de crescimento, conforme demonstra a tabela 1 .

\section{TABELA 1}

PARÂMETROS DE GRADUAÇÃo HISTOLÓGICA E GRAVIDAdE DAS LESÕES NA OSTEOARTRITE QUE COMPÕEM O ESCORE DE MANKIN

\begin{tabular}{llcr}
\hline I. Estrutura & \multicolumn{3}{c}{$\begin{array}{c}\text { III. Coloração com } \\
\text { azul de anilina }\end{array}$} \\
\hline Normal & 0 & Normal & 0 \\
$\begin{array}{l}\text { Pannus e irregularidades } \\
\text { na superfície }\end{array}$ & 1 & Leve redução & 1 \\
\hline $\begin{array}{l}\text { Irregularidades na superfície } \\
\text { Fissuras para a região transicional }\end{array}$ & 2 & Moderada redução & 2 \\
\hline Fissuras para a zona radial & 4 & Grande redução & 3 \\
\hline $\begin{array}{l}\text { Fissuras para a zona } \\
\text { de calcificação }\end{array}$ & 5 & & 4 \\
\hline Desorganização completa & 6 & & \\
\hline II. Celularidade & & IV. Integridade & \\
\hline Normalo & da linha de crescimento & \\
\hline Hipercelularidade difusa & 1 & Atravessada por vasos sangüíneos & 1 \\
\hline Clones & 2 & & 0 \\
\hline Hipocelularidade & 3 & & \\
\hline
\end{tabular}




\section{ANÁLISE ESTATÍSTICA}

Para analisar o efeito do difosfato de cloroquina no modelo de OA, foi utilizado o teste das diferenças e associações na freqüência de variáveis morfológicas, utilizando o teste de $\mathrm{T}$ para amostras independentes. O método estatístico utilizado para este estudo foi obtido pela versão 10.0 do programa SPSS $^{(22)}$, e o nível de significância estabelecido foi de $5 \%$.

\section{IMUNOFLUORESCÊNCIA PARA OS TIPOS DE COLÁGENOS}

Para a imunofluorescência foi utilizada uma série de quatro secções histológicas de cada animal, representativas de regiões diferentes da articulação. Os cortes histológicos das articulações, de aproximadamente $3 \mu \mathrm{m}$ de espessura, foram aderidos às lâminas previamente tratadas com aminosilano. Os cortes foram desparafinizados em xilol e hidratados com banhos de álcool etílico, com concentrações decrescentes (100\% a 75\%), água corrente (dez minutos), água destilada e tampão PBS. Posteriormente procedeu-se a digestão enzimática: com condroitinase $\mathrm{ABC} 2 \mathrm{U} / \mathrm{mL}$ dissolvida em tampão Tris- $\mathrm{HCl} 0,05 \mathrm{M}$ pH 8,0 por três horas a $37^{\circ} \mathrm{C}$, seguida de digestão com pepsina em ácido acético $0,05 \mathrm{~N}$, durante 30 minutos.

Os cortes tratados foram lavados três vezes por dez minutos, com PBS, e incubados por uma noite, com os anticorpos anticolágenos dos tipos I, II e XI policlonais produzidos em camundongos em nosso laboratório, na diluição de 1:200. Após esse período, os cortes foram lavados em PBS com Tween $20,05 \%$ e incubados por 90 minutos com anticorpo secundário anti-IgG de camundongo conjugado com fluoresceína (Sigma), diluído 1:50 com solução de azul de Evans $3 \mathrm{mg}$ por cento em PBS. Por fim, as lâminas foram lavadas com PBS - Tween 20 0,05\%, montadas com glicina tamponada, e a reação visualizada em um microscópio de fluorescência (NIKON).

\section{RESULTADOS}

\section{CARACTERIZAÇÃO DO MODELO \\ EXPERIMENTAL DE OSTEOARTRITE}

\section{ALterações macroscópicas e histológicas}

A figura 1 mostra o aspecto macroscópico dos côndilos do fêmur de um animal normal (painel A) e animais com OA, após indução da doença, sacrificados após três semanas (painel B), 14 semanas (painel C) e 22 semanas (painel D). A freqüência e a gravidade das fibrilações na cartilagem articular dos joelhos de coelhos com meniscectomia parcial (joelho direito) nos grupos com 3, 14 e 22 semanas tiveram uma tendência ao aumento em função do tempo da doença (Gráfico 1).
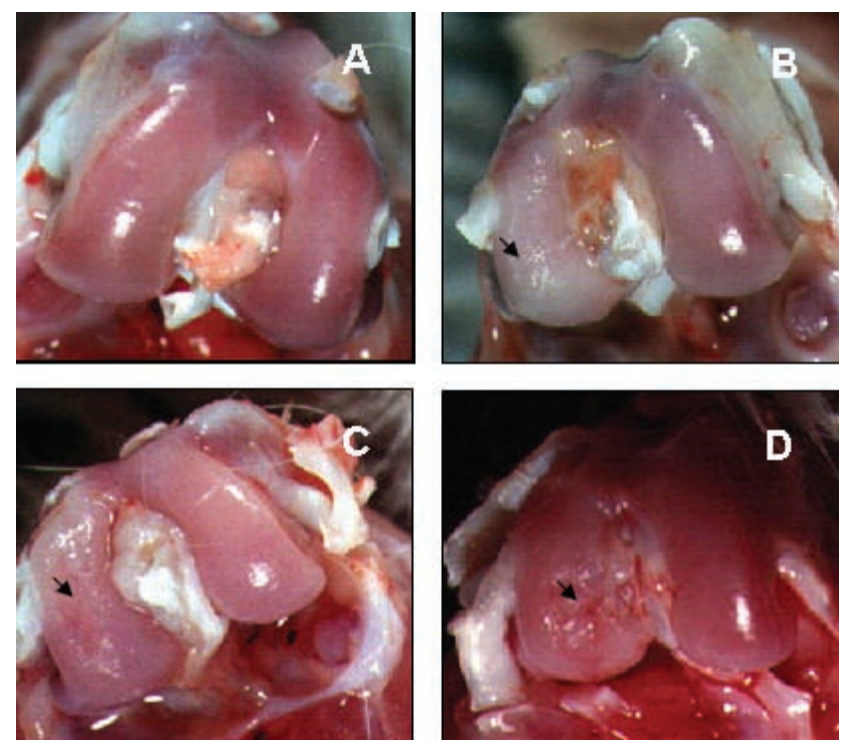

Figura 1 - Aparência macroscópica da cartilagem dos côndilos do fêmur de coelhos controle normal (A), com três (B), 14 (C) e 22 (D) semanas de 0A induzida. Notar fibrilações na superfície da cartilagem do animal com três semanas de doença (B) (setas). As fibrilações foram mais profundas nos grupos com 14 (C) e 22 (D) semanas de doença, mostrando erosões na região central dos côndilos e platôs laterais (setas). 

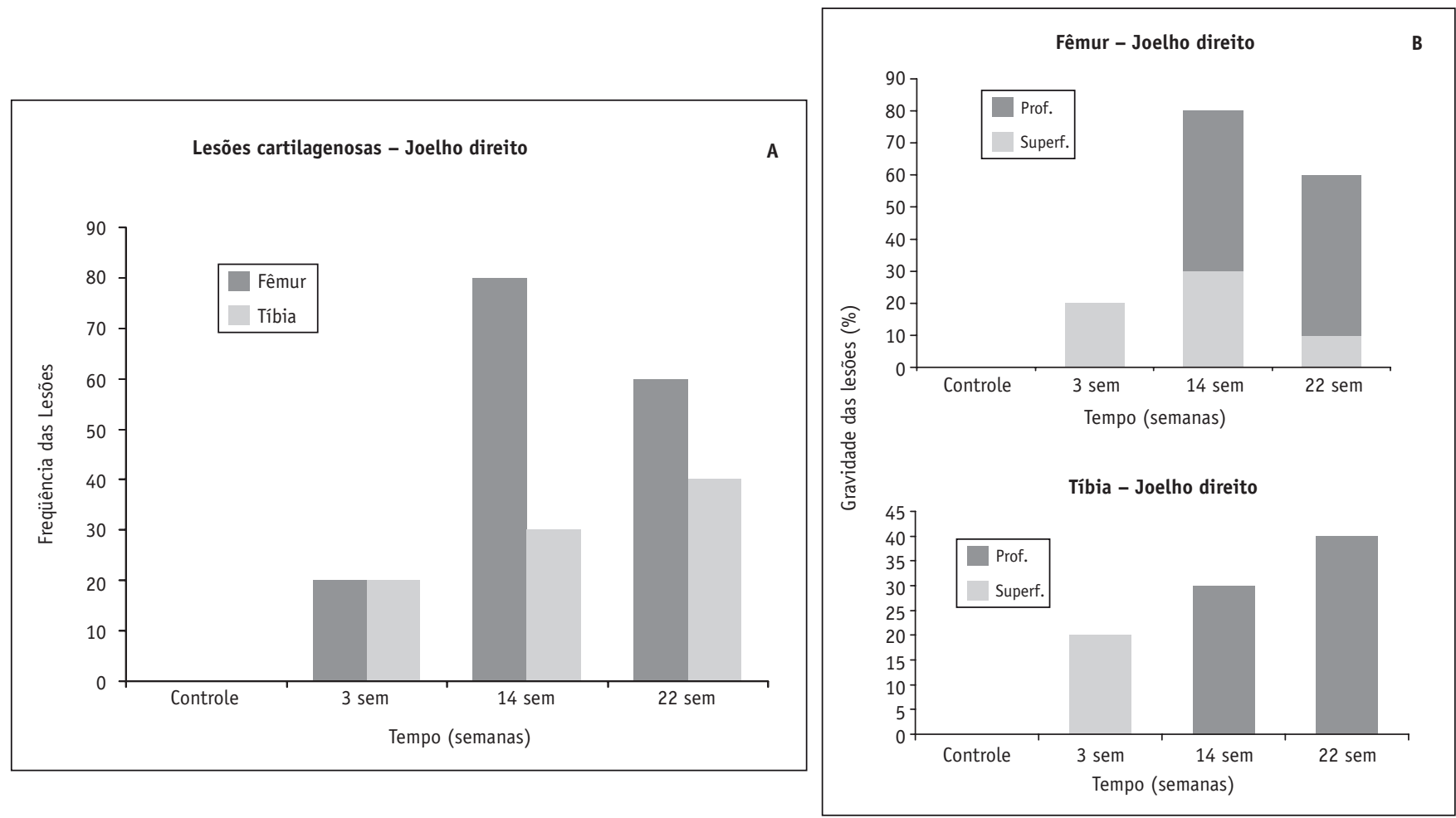

Gráfico 1 - Freqüência das lesões na cartilagem articular do joelho direito (meniscectomizado) (A) e gravidade destas lesões (B) nos grupos de animais com 3 , 14 e 22 semanas de osteoartrite experimental.

Na tabela 2, encontra-se a frequiência de osteófitos observados nos joelhos de coelhos com meniscectomia parcial (joelho direito) e joelho contralateral não operado (joelho esquerdo) nos grupos de animais com três, $14 \mathrm{e}$ 22 semanas de OA experimental.

\section{TABELA 2}

Percentagem de animais com osteófitos nos joelhos DIREITO (OPERADO) E ESQUERDO (NÃO OPERADO)

NOS GRUPOS DE ANIMAIS COM 3, 14 E 22 SEMANAS DE OSTEOARTRITE EXPERIMENTAL E CONTROLE

\begin{tabular}{lcccc}
\hline \multirow{2}{*}{$\begin{array}{c}\text { OSUPO } \\
(\mathrm{n}=10)\end{array}$} & JOELHO DIREITO $(\%)$ & JOELHO ESQUERDO(\%) \\
& Fêmur & Tíbia & Fêmur & Tíbia \\
\hline 3 Sem. & 20 & 10 & - & - \\
14 Sem. & 50 & 30 & - & - \\
22 Sem. & 50 & 10 & 20 & - \\
Controle & - & - & - & - \\
\hline
\end{tabular}

Na figura 2, A e B, encontram-se os aspectos histológicos da cartilagem articular de um animal normal corada, respectivamente, pelo $\mathrm{H} \& \mathrm{E}$ e tricrômico de Masson. Mudanças histológicas na cartilagem articular de joelhos operados, compatíveis com as encontradas na OA, foram um achado comum em três semanas (Figuras $3 \mathrm{C}$ e D), 14 semanas (Figuras 3 E e F) e 22 semanas de doença (Figuras $3 \mathrm{G} \mathrm{e} \mathrm{H}$ ).

\section{ANÁLISE MORFOLÓGICA DA CARTILAGEM APÓS \\ TRATAMENTO COM DIFOSFATO DE CLOROQUINA}

A figura 3 demonstra cortes de cartilagem de coelhos normais (figuras $3 \mathrm{~A}$ e B), com 22 semanas após a indução de $\mathrm{OA}$ (figuras $3 \mathrm{C}$ e D) e animais com $\mathrm{OA}$ tratados com o difosfato de cloroquina (figuras $3 \mathrm{E}$ e F), corados respectivamente pelas técnicas de $\mathrm{H} \& \mathrm{E}$ e tricrômico de Masson.

Pode-se observar que a cartilagem articular dos coelhos tratados com o difosfato de cloroquina (figura $3 \mathrm{E} \mathrm{e} \mathrm{F}$ ) 

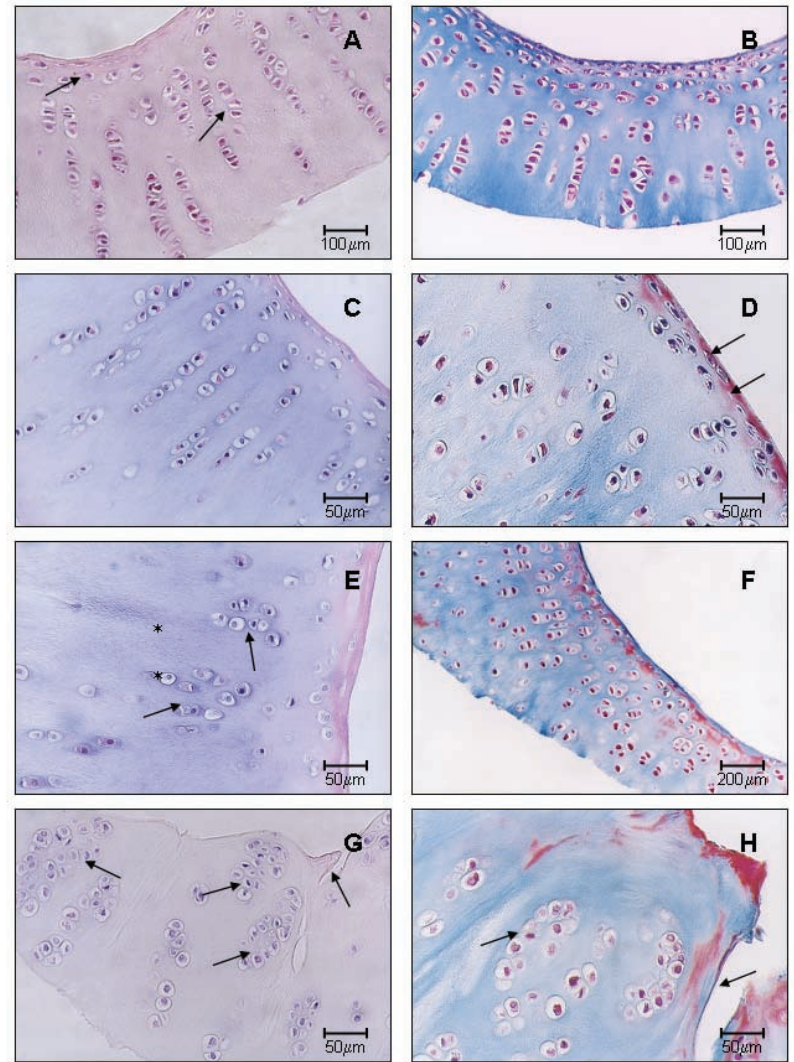

Figura 2 - Cortes transversais da cartilagem articular de animal normal (A e B), com três ( $C$ e D), 14 (E e F) e 22 ( $\mathrm{G} \mathrm{e} \mathrm{H}$ ) semanas de $0 A$ experimental com H\&E (lado esquerdo) e tricrômico de Masson (lado direito). Notar o padrão normal de organização celular, com células achatadas e dispostas em camadas na superfície celular e dispostas em pilhas em regiões mais profundas (setas) (A), além do padrão homogêneo de coloração pelo tricrômico de Masson (B). Com três semanas de $0 A$ induzida observam-se desorganização celular (C) e alterações no padrão de coloração pelo tricrômico de Masson na região superficial da cartilagem (setas) (D). Já com 14 semanas de doença, encontram-se presença de pequenos grupos de células (setas) (E) e alterações na coloração do tricrômico de Masson desde a superfície até regiões mais profundas (F). Em 22 semanas de $0 \mathrm{~A}$ experimental, ocorrem fissuras, hipercelularidade difusa, com aglomerados de células em clones (setas) (G) e intensa alteração na coloração pelo tricrômico de Masson. $H \& E$; tricrômico de Masson: F, X100; A,B, X200; C,D,E,G,H, X400.

apresentou-se estruturalmente preservada com um padrão de orientação celular semelhante aos encontrados em animais-controles, com condrócitos da superfície articular dispostos em camadas e empilhados nas regiões intermediárias (figura $3 \mathrm{E}$ ), conservação da linha de crescimento entre a cartilagem e o osso (figura $3 \mathrm{E}$ ), além de apresentar padrão homogêneo de coloração em azul de todo o tecido corado pelo tricrômico de Masson mostrando preservação da rede matricial de colágenos (figura $3 \mathrm{~F}$ ).
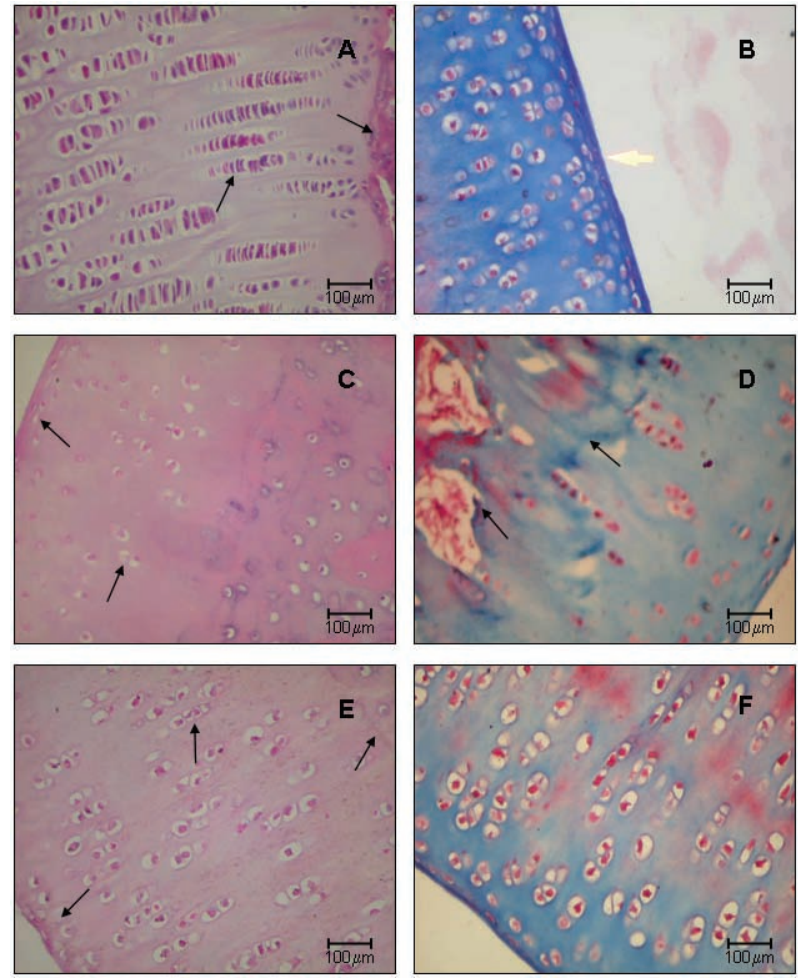

Figura 3 - Cortes transversais da cartilagem articular de joelhos de coelhos corados por H\&E (lado esquerdo) e pelo tricrômico de Masson (lado direito). Em A, cartilagem articular normal mostrando condrócitos dispostos paralelamente à região superficial e empilhados na região intermediária (setas). Em B, observase em azul a rede de colágeno, apresentando um padrão homogêneo em toda a matriz cartilagenosa, desde a superfície da cartilagem, na matriz territorial dos condrócitos, assim como na zona intermediária. Após 22 semanas de indução de $0 \mathrm{~A}$ experimental, observam-se perda dos condrócitos na superfície e desorganização das pilhas de células nas regiões intermediárias (setas) (C), além de apresentar padrão heterogêneo e perda de coloração da matriz cartilaginosa e aspecto difuso da linha de crescimento, com invasão da matriz óssea (setas) (D). Em E, cartilagem de animal operado após tratamento com difosfato de cloroquina, destacando-se o padrão de orientação celular semelhante aos animais-controle, além de conservação da linha de crescimento (setas). Em F, neste último grupo de animais, observa-se coloração mais homogênea da matriz cartilaginosa. H\&E; Tricrômico de Masson: $A, B, C, D, E, F ; 200 X$.

\section{ANÁLISE SEMIQUANTITATIVA DAS ALTERAÇÕES DA CARTILAGEM}

$\mathrm{Na}$ tabela 3, encontra-se a análise semiquantitativa pelo escore de Mankin das alterações observadas na cartilagem de animais com 22 semanas de OA e animais tratados com difosfato de cloroquina. Foi observada diferença significativa na cartilagem dos animais com OA tratados com difosfato de cloroquina quanto à estrutura da cartilagem $(\mathrm{p}<0,0001)$, celularidade $(\mathrm{p}<0,0001)$, coloração pelo azul de anilina $(\mathrm{p}<0,005)$ $\mathrm{e}$ integridade da linha de crescimento $(\mathrm{p}<0,001)$. 
TABELA 3

OS ESCORES SEMIQUANTITATIVOS DAS ALTERAÇÕES DA CARTILAGEM REPRESENTADOS PELA MÉDIA E DESVIO PADRÃO QUANTO A ESTRUTURA DA CARTILAGEM, CELULARIDADE, INTENSIDADE DE COLORAÇÃO PELO AZUL DE ANILINA E INTEGRIDADE DA LINHA DE CRESCIMENTO EM CORTES HISTOLÓGICOS EXAMINADOS DE ANIMAIS COM OSTEOARTRITE COM E SEM TRATAMENTO COM DIFOSFATO DE CLOROQUINA*

\begin{tabular}{lccc}
\hline & \multicolumn{1}{c}{$\mathbf{0 A}$} \\
$(\mathbf{n = 6})$ & $\begin{array}{c}\text { Difosfato de cloroquina } \\
(\mathbf{n = 6})\end{array}$ & $\mathbf{p}$ \\
\hline $\begin{array}{l}\text { Estrutura da } \\
\text { cartilagem }\end{array}$ & $5,14 \pm 0,37$ & $0,58 \pm 0,50$ & 0,0001 \\
$\begin{array}{l}\text { Celularidade } \\
2,57 \pm 0,53\end{array}$ & $0,53 \pm 0,51$ & 0,0001 \\
$\begin{array}{l}\text { Coloração pelo } \\
\text { azul de anilina }\end{array}$ & $2,28 \pm 0,48$ & $1,58 \pm 0,50$ & 0,005 \\
$\begin{array}{l}\text { Linha de cresci- } \\
\text { mento }\end{array}$ & $1,0 \pm 0,29$ & $0 \pm 0,11$ & 0,001 \\
\hline
\end{tabular}

* Análise estatística feita de acordo com o teste de amostras independentes

\section{ANÁLISE DA IMUNOMARCAÇÃO PARA COLÁGENO}

O colágeno tipo I foi expresso na cartilagem de animais com 22 semanas de OA (figura 4 B), estando ausente em cartilagem de animais meniscectomizados e tratados com o difosfato de cloroquina (figura $4 \mathrm{C}$ ), semelhante ao padrão normal na cartilagem (figura $4 \mathrm{~A}$ ). Ao contrário, o colágeno tipo II, específico de cartilagem, apresentou-se menos expresso em cartilagem de animais com OA (figura $4 \mathrm{E}$ ), porém com aumento de expressão após tratamento com difosfato de cloroquina (figura $4 \mathrm{~F}$ ), semelhante à cartilagem normal (figura 4 D). Na cartilagem dos animais não tratados, foi também encontrada diminuição na marcação do tipo XI (figura $4 \mathrm{H}$ ), com padrão mais pericelular, porém após tratamento com difosfato de cloroquina, observou-se um padrão de marcação mais homogêneo através da matriz extracelular (figura 4 I), como o encontrado na cartilagem normal (figura $4 \mathrm{G}$ ).

\section{DISCUSSÃO}

O estudo das alterações morfológicas que ocorrem na cartilagem em pacientes com OA sintomática inicial é difícil, uma vez que as alterações cartilaginosas nesse estágio não são visualizadas pelas metodologias habituais de imagem e tampouco seria possível do ponto de vista ético a obtenção de amostras para estudos. Essas razões explicam a dificuldade de estudar a ação de fármacos sobre os tecidos articulares em humanos.

Apesar de os modelos experimentais em animais refletirem uma forma de OA secundária, estes possibilitam um
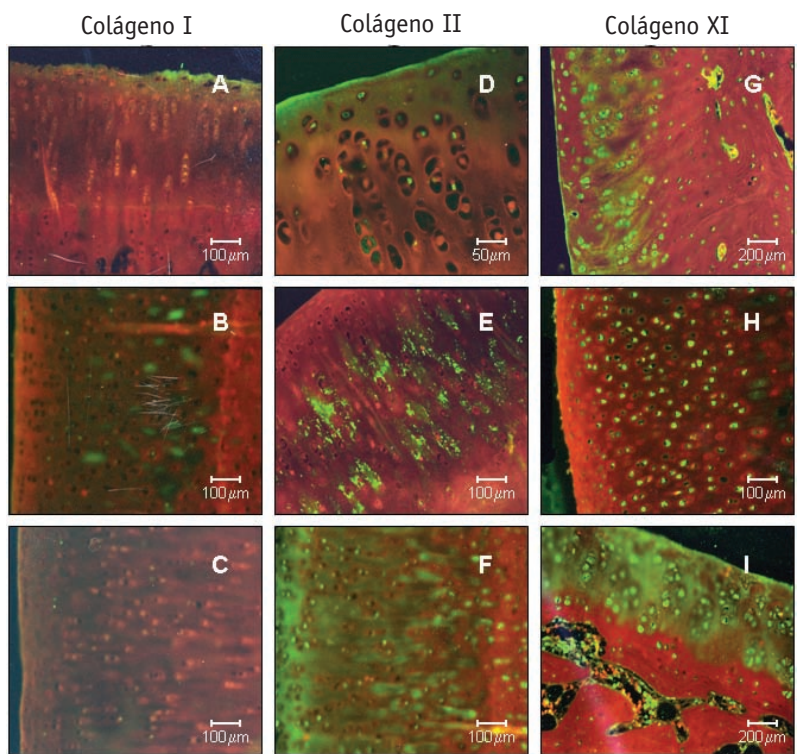

Figura 4 - Imunofluorescência em cortes transversais de cartilagem articular de joelho de coelho. Em A, marcação negativa para o colágeno tipo I em cartilagem normal. Em B, positividade para o colágeno tipo I, na cartilagem articular após 22 semanas de indução da doença. Em C, evidencia-se a marcação negativa para colágeno do tipo I, após tratamento com difosfato de cloroquina. Em D, colágeno do tipo II em cartilagem normal, mostrando um padrão homogêneo de marcação. Após 22 semanas de indução da doença, observa-se positividade para colágeno tipo II na matriz pericondrocitária (E). Em F, após tratamento com difosfato de cloroquina, observa-se a manutenção da positividade do colágeno tipo II em toda a matriz cartilaginosa. Em G, cartilagem articular normal, mostrando positividade para o colágeno do tipo XI na região superficial e na matriz intermediária dos condrócitos. Após 22 semanas de indução da doença, observam-se ausência de marcação para colágeno do tipo XI na região superficial e presença somente na matriz territorial condrocitária $(H)$. Em I, cartilagem articular após tratamento com difosfato de cloroquina, observa-se preservação da positividade para colágeno do tipo XI em toda matriz cartilaginosa, semelhante ao padrão normal. Imunofluorescência: $A, B, C, E, F, G, H, I, X 200 ; D, X 400$.

monitoramento mais preciso da doença, tornando viável o estudo macroscópico, histológico, bioquímico e molecular da cartilagem em diferentes estágios da doença. Estudos utilizando modelos experimentais em animais, indiscutivelmente, fornecem dados importantes ao entendimento da fisiopatologia da OA e da ação terapêutica de diversas drogas.

Contudo, existem diferenças quanto à evolução temporal da OA experimental em animais e em humanos e, certamente, a escolha da espécie animal também terá grande influência nos resultados. Recentemente, temos trabalhado com modelo de OA, que ocorre espontaneamente em cachorros de determinadas raças (boxer, pit-bull, labrador), após lesão do ligamento cruzado do joelho. A evolução da degeneração articular é dramática, pois em poucas semanas ocorre destruição articular, evidenciada clínica e radiologicamente, mostrando que animais comportam-se de forma diferente dos humanos. Ressaltando-se que realização de 
exames de imagens são procedimentos complicados em animais de pequeno porte como ratos e coelhos, porém exeqüíveis nos maiores como cachorros. É possível que no futuro o cachorro com artrose pós-traumática seja um dos modelos ideais no estudo da OA experimental, especialmente porque, além de ético, por não causar sofrimento animal, aproveita-se a necessidade da realização de estabilização cirúrgica do joelho, para proceder a coleta de sinóvia, cartilagem e fluido sinovial para a pesquisa.

A meniscectomia parcial em coelhos produz mudanças que são similares às lesões vistas em $\mathrm{OA}$ em humanos ${ }^{(20)}$. Entretanto, a freqüência e a gravidade das alterações osteocartilaginosas no curso da doença dependem de quanto da articulação é desestabilizada cirurgicamente ${ }^{(23,24)}$. Desse modo, para estudar a progressividade das alterações histológicas na cartilagem articular, desde seus estágios mais iniciais, optamos pela indução da doença experimental, por meio de uma desestabilização articular mais branda, em relação aos modelos normalmente encontrados na literatura $^{(20,23)}$, sem o corte dos ligamentos colaterais e cruzados e com a remoção de uma pequena porção do menisco. Nosso objetivo foi desenvolver um modelo de OA com alterações gradativas, para melhor simular a doença degenerativa crônica em humanos, visando a permitir o estudo da ação de fármacos em animais com OA experimental.

Certamente que, ao se induzir uma $\mathrm{OA}$ de evolução mais lenta, aproximando o modelo experimental do que é observado em humanos, os fármacos terão maior chance de atuar no processo fisiopatológico envolvido na degradação articular, especialmente quando a droga é ministrada antes mesmo da indução da enfermidade, como foi o que ocorreu com o emprego da cloroquina no presente estudo. Os resultados do trabalho foram dramáticos, porém devemos lembrar que, em doentes com artrose, a droga é iniciada quando a lesão articular já está instalada. É possível que a cloroquina ministrada precocemente tenha promovido inibição igualmente precoce e mantida das citocinas próinflamatórias como a IL- 1 e TNF- $\alpha$, bloqueando o processo catabólico da cartilagem articular. Contudo vale lembrar que a cloroquina é utilizada empiricamente no Serviço de Reumatologia da Faculdade de Medicina da Universidade de São Paulo (FMUSP) há quase 30 anos com bons resultados práticos, antes mesmo do surgimento dos novos condroprotetores no mercado.

No modelo de meniscectomia, o surgimento de osteófitos e a formação de fibrilações na cartilagem articular aconteceram durante a evolução da $\mathrm{OA}$, como observado por outros autores ${ }^{(23)}$, porém no nosso caso, de forma mais lenta. As alterações histológicas mostraram a existência de um padrão progressivo de desorganização celular e as alterações na malha de colágeno, conforme a evolução da doença. Interessante observar que o joelho contralateral igualmente desenvolveu em menor escala sinais de OA, como demonstrado pela presença de raros osteófitos.

Em suma, esse modelo experimental de meniscectomia parcial em coelhos, que promove alterações morfológicas, histológicas e bioquímicas graduais, abriu um campo de pesquisa, no sentido de testarem-se drogas potencialmente efetivas no tratamento da OA como os antimaláricos.

Pesquisas clínicas com drogas antimaláricas na OA praticamente inexistem na literatura. Bryant et al., em 1995(25), por intermédio da análise retrospectiva de oito pacientes com OA erosiva, que receberam difosfato de cloroquina, sugeriram como promissor o emprego dessa droga nessa enfermidade. Os antimaláricos, especialmente o composto químico hidroxicloroquina, são bastante utilizados no tratamento de artrite reumatóide e lúpus eritematoso sistêmico, e muitas de suas propriedades biológicas já são conhecidas.

As principais ações farmacológicas conhecidas dos antimaláricos são: inibição da fosfolipase $\mathrm{A}$, estabilização da membrana de lisossomas, inibição da quimiotaxia e fagocitose de polimorfonucleares, inibição na geração de superóxido, diminuição na produção de fibronectina, inibição na agregação eritrocitária intravascular, diminuição da agregação plaquetária, fotoproteção cutânea, inibição da degradação cartilaginosa induzida pela interleucina 1 . Dentre as propriedades imunológicas da droga, podem ser citadas: a inibição da produção de citocinas próinflamatórias, diminuição da síntese de anticorpos e autoanticorpos, inibição da resposta linfoproliferativa, inibição da ação das células natural killer, inibição da formação de imunecomplexos ${ }^{(26)}$.

Em virtude de diferentes propriedades biológicas da cloroquina, compreende-se que essa droga seria útil no tratamento da $\mathrm{OA}$, enfermidade atualmente entendida como inflamatória e não apenas degenerativa, como se imaginava no passado. Contudo, desconhece-se o local da atuação dos antimaláricos. Admite-se a possibilidade da ação ao nível das citocinas, bloqueando a atividade catabólica da IL-1 e/ou TNF- $\alpha$ sintetizados por condrócitos ou células sinoviais inflamadas; ou modificando a síntese de prostaglandina E2 que regula a síntese das citocinas; ou influenciando na produção das metaloproteases, que são as enzimas catabólicas da matriz extracelular.

Nosso objetivo foi verificar se o difosfato de cloroquina, droga barata, de aquisição fácil pelos pacientes e que existe 
no nosso complexo hospitalar, teria ação condroprotetora, quando administrado na dose de $3 \mathrm{mg} / \mathrm{kg}$ ao dia no coelho submetido à $\mathrm{OA}$ experimental por meniscetomia parcial. Assim, o fármaco foi administrado oralmente um mês antes da realização da meniscectomia e mantido durante 22 semanas. Na verdade, esse procedimento experimental não reproduz exatamente as condições clínicas habituais, pois os doentes que recebem o medicamento já estão sintomáticos, com a OA em evolução. Contudo, sabemos que os antimaláricos são drogas de depósito que apenas atuam quando estão presentes em concentrações efetivas nos tecidos, e essa foi a principal justificativa a ser lembrada quando se programou o desenho da pesquisa. Adicionalmente, sabemos que as alterações morfológicas após indução da $\mathrm{OA}$ em coelhos acontecem rapidamente em questão de dias a semanas, impossibilitando a atuação plena das drogas de depósito. Finalmente, o grande objetivo do trabalho seria o de responder se a cloroquina teria alguma ação terapêutica, independentemente de quando a droga fora introduzida. Certamente que novos experimentos serão projetados no futuro, incluindo animais já doentes de OA, com a finalidade de saber se a droga seria eficaz em modificar o curso clínico de uma patologia já instalada e também saber se é possível a reversão de determinados aspectos morfológicos e funcionais das articulações já acometidas.

\section{REFERÊNCIAS}

1. Mendler M, Eich-Bender SG, Vaughan L, Winterhalter KH, Bruckner P: Cartilage contains mixed fibrils of types II, IX, and XI. J Cell Biol 108: 191-7, 1989.

2. Eyre DR: The collagens of articular cartilage. Semin. Arthritis Rheum 21(3): 2-11, 1991.

3. Eyre DR, Wu J-J: Collagen structure and cartilage matrix integrity. J Rheumatol S43: 82-5, 1995.

4. Pfander D, Rahmanzadeh R, Scheller EE: Presence and distribution of collagen II, collagen I, fibronectin, and tenascin in rabbit normal and osteoarthritic cartilage. J Rheumatol 26(2): 386-94, 1999.

5. Gregory K, Oxford JT, Chen Y: Structural Organization of distinct domains within the non-collagenous $\mathrm{N}$-terminal region of collagen type XI. J Biol Chem 275(15): 1498-506, 2000.

6. Eyre DR, Apone S, Wu J-J, Ericsson LH, Walsh KA: Collagen type IX: Evidence for covalent linkages to type II collagen in cartilage. FEBS Lett 220: 337-41, 1987.

7. Olsen BR: Collagen IX. Int J Biochem Cell Biol 29: 555-8, 1997.

8. Burgeson RE, Hollister DW: Collagen heterogeneity in human cartilage: identification of several new collagen chains. Biochem Biophyis Res Commun, Duluth 87(4): 1124-31, 1979.
Demonstramos pela primeira vez que o difosfato de cloroquina inibiu a progressão da $\mathrm{OA}$ secundária a traumas, preservando significantemente a arquitetura morfológica da articulação, como a estrutura da cartilagem, a organização celular e principalmente a linha de crescimento. Além disso, essa droga se mostrou eficaz quanto à conservação e à preservação da composição qualitativa dos principais colágenos presentes na cartilagem.

Os resultados obtidos pela imunofluorescência confirmaram os resultados histológicos neste modelo experimental de OA. A imunomarcação para o colágeno tipo XI no grupo de 22 semanas de OA experimental mostrou uma diminuição deste colágeno neste estágio de doença. O emprego do difosfato de cloroquina preservou a distribuição tecidual habitual dos colágenos dos tipos II e XI na matriz cartilaginosa, além de inibir o aparecimento do colágeno do tipo I, normalmente presente na OA em evolução. Concluímos que o difosfato de cloroquina é uma droga promissora no tratamento da $\mathrm{OA}$ humana, pois nos animais de experimentação esse fármaco conseguiu inibir o processo de remodelamento do tecido cartilaginoso, impedindo o surgimento de complicações morfológicas habitualmente presentes nessa enfermidade. Por tratar-se de droga de fácil acesso, e a osteoartrose ser a mais freqüente das enfermidades reumatológicas, essa modalidade de tratamento tem importante impacto social e médico.

9. Eyre DR, Paz M A, Gallop PM: Cross-linking in collagen and elastin. Ann Rev Biochem Palo Alto 53: 717-48, 1984.

10. Shimokomaki M, Duance VC, Bailey AJ: Identification of two further collagenous fractions from cartilage. Biosc Rep London l(7): 561-70, 1981.

11. Shimokomaki M, Duance VC, Bayley AJ: Identification of a new disulphide bonded collagen from cartilage, FEBS Letters, Amsterdam 121(1): 51-4, 1980.

12. Aigner T, Stoss H, Weseloh G, Zeiler G, von der Mark K: Activation of collagen type II expression in osteoarthritic and rheumatoid cartilage. Virchows Arch B Cell Pathol Incl Mol Pathol 62(6): 337-45, 1992.

13. Pfander D, Rahmanzadeh R, Scheller EE: Presence and distribution of collagen II, collagen I, fibronectin, and tenascin in rabbit normal and osteoarthritic cartilage. J Rheumatol 26(2): 386-94, 1999.

14. Reife RA, Nalin AM, Sandell LJ: Type IIA procollagen is reexpressed in osteoarthritis (abstr). Trans Orthop Res Soc 19: 267, 1994.

15. Ronzière M-C, Ricard-Blum S, Tiollier J, Hartmann DJ, Garrone R, Herbage D: Comparative analysis of collagens solubilized from human foetal, and normal and osteoarthritic adult articular 
cartilage, with emphasis on type VI collagen. Biochem Biophys 1038: 222-30, 1990.

16. Rivero MGC, Teodoro WR, Velosa APP, Witzel SS, Yoshinari NH: Caracterização bioquímica do colágeno do tipo VI na osteoartrose experimental. Rev Bras Reumatol 40(2): 65-70, 2000.

17. Hoyland JA, Thomas JT, Donn R, et al.: Distribution of type X collagen mRNA in normal and osteoarthritic human cartilage. Bone Miner 15(2): 151-63, 1991.

18. Nimni ME: Collagen: structure, function and metabolism in normal and fibrotic tissues. Semin Arthritis Rheum 13: 1-85, 1983.

19. Young RD, Lawrence PA, Duance VC, Aigner T, Monaghan P: Immunolocalization of type III collagen in human articular cartilage prepared by pressure cryofixation, freeze-substituition, and low-temperature embedding. J Histochem Cytochem 43: 421-27, 1995

20. Moskowitz RW, Davis W, Sammarco J, Mast W, Chase SW: Experimentally induced corticosteroid arthropathy. Arthritis Rheum 13(3): 236-43, 1970.
21. Mankin HJ, Dorfman H, Lippiello, Zarins A: Biochemical and metabolic abnormalities in articular cartilage from osteoarthritic human hips. II. Correlation of morphology with bioquemical and metabolic data. J Bone Joint Surg 53(3): 523-33, 1971.

22. SPSS Statistical software (2002) Version 10.0. SPSS Inc, Chicago.

23. Moskowitz RW, Davis W, Sammarco J, et al.: Experimentally induced degenerative joint lesions following partial meniscectomy in the rabbit. Arthritis Rheum 16(3): 397-405, 1973.

24. Hulth A, Lindberg L, Telhag H: Experimental osteoarthritis in rabbits. Acta Orthop Scandinav 41: 522-30, 1970.

25. Bryant LR, Des Rosier KF, Carpenter MT: Hydroxychloroquine in the treatment of erosive osteoarthritis. J Rheumatol 8: 1527-31, 1995.

26. Hardman JG, Limbird LE, Molinoff PB, Gilman AG: The pharmacological basic of therapeutics. 10.ed. New York: Pergamon-Press, 2001. 